\title{
Helen Salisbury: Should I persuade patients to have mammograms?
}

\author{
Helen Salisbury GP
}

Oxford

Our practice has recently been invited by the local clinical commissioning group to take part in a quality improvement scheme aimed at increasing the uptake of cancer screening. We are offered support from Cancer Research UK to make an action plan to improve rates of bowel, cervical, and breast cancer screening. We're incentivised with payments for engaging in the process and for any increase in the proportion of our patients screened.

I wish I could say that my conversations about cancer screening all adhere to guidelines about how to share decisions with patients. ${ }^{1}$ In reality, most of our exchanges are a very brief aside in a consultation about something else. If we do have time for more, the conversations about bowel and cervical cancer screening are relatively straightforward-for me, at least. I explore any reservations the patient has and try to explain the process and the pros and cons. As the evidence of benefit is robust, I can advise my patients that any disadvantages of taking these tests are very likely to be outweighed by the advantages of treating minor changes and preventing cancer.

But I have a problem with breast cancer screening. The evidence for its benefit is very much less clear. There are well known problems with lead time bias, overdiagnosis, and toxic treatments of screen detected "cancers" that would never have been clinically relevant. ${ }^{2}$

Michael Baum, an architect of the UK screening programme, said in a letter to the Times last week that "screening seems to be a zero sum game in that for every breast cancer death avoided there is one death from overtreatment of pseudocancers." He went on to say that it was time to de-implement screening. He is not alone in this. In 2017 the Swiss Medical Board reviewed the available evidence and concluded that no new systematic mammography programmes should be introduced in Switzerland.
A Cochrane review in 2013 concluded that, in every 2000 women invited for screening, one would avoid dying of breast cancer and 10 would have unnecessary treatment. ${ }^{3}$ However, the conclusions of the Independent UK Panel on Breast Cancer Screening report published the same year were entirely different: one breast cancer death prevented in every 235 patients screened. ${ }^{4}$

So, what do I tell my patients? When I share the ambiguity in the evidence, we will probably have a long conversation, because I sincerely don't know the answer to the question, "Should I have my mammogram?"-even for myself.

If, after this initiative, breast cancer screening rates rise at our practice, can I be sure that all patients have made a fully informed, shared decision? Or is there a risk that they will just have been advised by a trusted doctor to be screened? The fact that we're being offered a payment for this makes me very uncomfortable.

Competing interests: See www.bmj.com/about-bmj/freelance-contributors.

Provenance and peer review: Commissioned; not externally peer reviewed.

1 Elwyn G, Frosch D, Thomson R, et al. Shared decision making: a model for clinical practice. Gen Intern Med 2012;27:1361.

2 Cochrane Nordic. New study finds breast cancer screening leads to substantial overdiagnosis. https://nordic.cochrane.org/news/new-study-finds-breast-cancer-screening leads-substantial-overdiagnosis.

3 Gøtzsche PC, Jørgensen KJ. Screening for breast cancer with mammography. Cochrane Database Syst Rev 2013:6.CD001877. 10.1002/14651858.CD001877 pub5. 23737396 4 Marmot MG, Altman DG, Cameron DA, Dewar JA, Thompson SG, Wilcox M. The benefits and harms of breast cancer screening: an independent review. Br J Cancer 2013;108:2205-40. 10.1038/bjc.2013.177 23744281

Published by the BMJ Publishing Group Limited. For permission to use (where not already granted under a licence) please go to http://group.bmj.com/group/rights-licensing/ permissions 